\title{
Indicadores do ambiente ruminal e suas relações com a composição do leite e células somáticas em diferentes períodos da primeira fase da lactação em vacas de alta produção
}

\author{
Indicators of rumen environment and their relation with milk composition and somatic cells in the first \\ phase of lactation in high-yielding dairy cows
}

\author{
Rómulo Campos $^{1}$ Félix González ${ }^{2}$ Arlei Coldebella ${ }^{3}$ Felipe Cardoso $^{4}$
}

\section{RESUMO}

\begin{abstract}
No atual sistema internacional de pagamento do leite por qualidade, têm-se valorizado dois aspectos fundamentais: a contagem de células somáticas (CCS) e o conteúdo de sólidos totais. O primeiro fator depende da saúde da glândula mamária e o segundo, de maior importância econômica para os laticínios, está relacionado com o manejo alimentar e a raça dos animais. $O$ ambiente ruminal pode modificar a composição do leite, em especial o teor de gordura. A fonte principal de proteína nos ruminantes depende da síntese de proteína no rúmen. Os atuais sistemas de alimentação, usados em vacas de alta produção, predispõem os animais à apresentação de síndromes metabólicas o que direta ou indiretamente afeta a produção de leite. Objetivou-se, com o presente trabalho, relacionar indicadores do ambiente ruminal (tempo de redução com azul de metileno e $\mathrm{pH}$ ) e o $\mathrm{pH}$ da urina com a composição do leite (sólidos totais) e a CCS. Não foi encontrada associação estatística entre os parâmetros avaliados. Os valores médios dos sólidos não-gordurosos analisados no estudo foram inferiores ao limite estabelecido pela norma oficial do Brasil.
\end{abstract}

Palavras-chave: rumen, $p H$ ruminal, sólidos totais, qualidade do leite.

\section{ABSTRACT}

In the current international milk payment system, where the quality is the main factor; two fundamental aspects have acquired great importance: the somatic cells count and the amount of total solids. The first one depends on the health of the mammary gland and the second factor, which has more economic impact for the dairy industry, is directly related to feeding management and the cattle breed. The environment of the rumen can modify the composition of the milk, specially the fat percentage. The main source of protein in the ruminants depends on the synthesis of protein in the rumen. The current feeding systems used in high-yielding dairy cows, predispose them to the outcome of metabolic syndromes that directly or indirectly affect the milk production. The purpose of this study was to establish a relation between the index of the rumen environment (Methylene blue reduction time and $\mathrm{pH}$ ) and urinary $\mathrm{pH}$ with the composition of the milk and the somatic cells count. None statistical relation was found among the parameters evaluated. The average values of non fat solids in this study were below the official values approved in Brazil.

Key words: rumen, ruminal $p H$, total solids, milk composition.

\section{INTRODUÇÃO}

O mercado mundial de alimentos apresenta alta competitividade entre as indústrias processadoras. A necessidade de atender à exigente e instável demanda gera novos produtos para os quais se requer matéria prima de alta qualidade. Por outro lado, as políticas de geração de lucro máximo através de um maior valor agregado no produto e a diminuição nas vantagens comerciais simples dos commodities, têm transformado o mercado de lácteos (IBARRA, 2004). Todavia, nos últimos anos, a composição do leite cru da raça Holandesa em países com tradição leiteira e no Brasil têm se mantido nos mesmos níveis de sólidos, na média: 3,6\% de gordura, 3,2\% de proteína e 4,7\% de lactose

\footnotetext{
${ }^{1}$ Programa de Pós-graduação em Ciências Veterinárias, Universidade Federal do Rio Grande do Sul (UFRGS). Porto Alegre, RS, Brasil. E - mail: romulo.campos@ufrgs.br Autor para correspondência. Rua Uapromá, 149, Apto 402, 31310.180, Belo Horizonte, MG.

${ }^{2}$ Departamento de Patologia Clínica, Faculdade de Veterinária, UFRGS, Porto Alegre, RS, Brasil

${ }^{3}$ Empresa Brasileira de Pesquisa Agropecuária (EMBRAPA), Suínos e Aves, Concórdia, SC, Brasil

${ }^{4}$ Serviços Veterinários (SerVet), Passo Fundo, RS, Brasil
} 
(KENNELLY et al., 2000, NORO, 2004). No entanto, por rentabilidade, as indústrias procuram maiores teores de proteína, em especial de caseína, e de gordura no leite.

A qualidade do leite como alimento e como matéria prima para a indústria de laticínios depende da sua composição, derivada em parte dos fatores nutricionais, da fermentação ruminal e do metabolismo endógeno da vaca (FREDEEN, 1996). Dos componentes do leite, o teor de gordura pode variar em função da alimentação e da raça. A tendência observada é que este teor diminui quando a produção aumenta. Alterações no teor de gordura podem informar sobre a fermentação no rúmen, as condições de saúde da vaca e do manejo alimentar. O teor de proteína no leite também pode ser afetado, porém, em menor grau, enquanto o teor de lactose é o menos afetado (BACHMAN, 1992).

Por volta de $50 \%$ dos precursores das moléculas de gordura sintetizadas na glândula mamária são gerados durante a fermentação ruminal. A porcentagem de gordura pode ser influenciada positivamente pelos altos níveis molares de ácidos acético e butírico, e negativamente pela porcentagem molar de ácido propiônico. Conseqüentemente, fatores da dieta que estimulam a produção de ácido propiônico ou alteram a relação propionato- acetato interferem na síntese de gordura no leite (KENNELLY et al., 2000).

A contagem de células somáticas (CCS) temse considerado como um dos indicadores de qualidade do leite. Através da sua determinação pode ser monitorado indiretamente o estado de saúde da glândula mamária (SANTOS, 2005).

A fisiologia do rúmen exige teores de material fibroso que regula o pH e influencia a dinâmica de crescimento da população bacteriana dentro do rúmen. Os desequilíbrios no $\mathrm{pH}$ ruminal, produzidos pela fibra inadequada na dieta, podem levar à apresentação de acidose ruminal clínica ou subclínica (KLEEN et al., 2003). Junto com a queda do pH, as relações entre os diferentes tipos de bactérias mudam (MARTIN, 1998). Sob estas condições, a produção de proteína bacteriana e de ácidos graxos voláteis pode se alterar levando à queda no consumo alimentar, causando menor síntese de leite e mudança na sua composição (BACHMAN, 1992). Outra conseqüência derivada está relacionada com a apresentação de desequilíbrios metabólicos (cetose, deslocamento de abomaso) que afetam a saúde e a rentabilidade da produção animal (OETZEL, 2001).

A determinação do $\mathrm{pH}$ do rúmen apresenta alguns inconvenientes derivados da dificuldade de obter uma amostra representativa do líquido do rúmen, uma vez que dentro do compartimento, existem diferentes estratos alimentares e concentrações de ácidos voláteis (KLEEN et al., 2003). Alguns trabalhos têm explorado a possibilidade de avaliar o $\mathrm{pH}$ ruminal mediante uma medição indireta feita na urina (ORTOLANI, 2002) na tentativa de solucionar o problema da amostragem de líquido do rúmen.

O tempo de redução de azul de metileno da microbiota ruminal (TRAM) constitui uma prova simples para estudar o potencial redox. Está baseada na redução de azul de metileno da forma corada para sua leucoderivada. Quanto maior quantidade de bactérias, maior taxa de redução e desaparecimento mais rápido da cor azul (SORIANO et al., 2000).

Na literatura, encontram-se trabalhos que avaliam a composição do leite após manipulações nutricionais, uso de aditivos ou de hormônios. Em alguns desses trabalhos, o rúmen foi monitorado, no entanto, não foram encontrados trabalhos que monitorem o ambiente ruminal em forma rotineira como ferramenta no estudo da qualidade do leite.

O objetivo do presente trabalho foi avaliar a relação entre os indicadores do ambiente ruminal ( $\mathrm{pH}$ e TRAM), o pH da urina e dois indicadores nutricionais: uréia e $\beta$-hidroxibutirato no soro, com a composição do leite e a CCS em diferentes períodos da primeira fase da lactação em vacas leiteiras de alta produção.

\section{MATERIAL E MÉTODOS}

No presente trabalho, foram utilizadas 140 vacas multíparas da raça Holandesa com produções médias superiores a $25 \mathrm{~kg} \mathrm{dia}^{-1}$, pertencentes a cinco rebanhos com sistema de produção intensiva para as condições do Rio Grande do Sul. A base da alimentação foi pastagem Tifton (Cynodon niemfluesis), silagem de sorgo e de milho, concentrado e suplemento mineral. O cálculo nutricional foi conferido mediante o programa Spartan Ration Evaluator versão 2.02b (Michigan State University, 2002).

Os animais foram amostrados nas semanas 2, 5, 8 e 11 de lactação, sendo selecionados sete animais em cada período e rebanho. As informações finais correspondem a 130 animais. Dez animais foram retirados do experimento por apresentar sinais evidentes de alteração patológica (cetose, deslocamento de abomaso). Em cada período, foram coletadas amostras de líquido ruminal através de sonda estomacal de dupla via (Haptner®, Solingen, Deustch) e abre-boca tubular. A sonda de coleta intra-ruminal foi adaptada com uma ponteira com grade, para evitar entupimento por partículas de material ruminal. Adicionalmente, a ponteira permitia a coleta de líquido 
da parte ventral do rúmen devido a seu peso e comprimento.

As coletas foram efetuadas após ordenha da manhã. Foi calculada uma média de três horas entre a última ingestão de comida e a hora da coleta. A amostra de líquido ruminal foi de no mínimo $250 \mathrm{~mL}$. Os primeiros jatos obtidos foram desprezados para reduzir o efeito da saliva arrastada pela sonda. O líquido obtido foi filtrado mediante adaptação de gaze dupla dentro de um funil. Numa parte do líquido filtrado, determinouse o $\mathrm{pH}$ através de potenciômetro digital. A outra parte de líquido foi vertida em dois tubos de ensaio previamente calibrados para um volume de $10 \mathrm{~mL}$ cada. Num dos tubos, testemunha, foram depositados $10 \mathrm{~mL}$ de líquido ruminal filtrado. O outro tubo continha $0,5 \mathrm{~mL}$ de uma solução 0,03\% de azul de metileno ao qual foram adicionados 9,5mL de líquido ruminal. A partir do momento da mistura do corante com o líquido ruminal, o tempo foi cronometrado, sendo registrado o tempo final de descoramento total do azul de metileno (TRAM) quando comparado ao tubo testemunha. A urina foi obtida por indução da micção por massagem perineal. Em recipientes esterilizados, foram recolhidos $100 \mathrm{~mL}$ de urina e, imediatamente após a coleta, determinado o $\mathrm{pH}$ da urina mediante potenciômetro digital. As amostras de sangue foram obtidas por venipunção coccígea mediante tubos vacutainer sem anticoagulante. Uma vez obtidas, foram refrigeradas, transportadas ao laboratório e submetidas à centrifugação a 3000rpm por 15 minutos para obtenção do soro, no qual foram determinados os metabólitos séricos uréia (NUS) e $\beta$-hidroxibutirato (BHB). As amostras de leite foram coletadas na ordenha da tarde. No processo, foram usados coletores especiais de amostragem de leite no sistema de ordenhadeiras. As amostras foram coletadas em frascos contendo o conservante bronopol (2-bromo, 2-nitro-1,3 propanediol) e remetidas antes de 24 horas para o Serviço de Análises de Rebanhos Leiteiros (SARLE Universidade de Passo Fundo), onde mediante o método de absorção de luz infra-vermelha (NIRS) e citometria de fluxo em aparelhos automatizados (Bentley Instruments Inc, Chaska, USA) foram determinados os componentes do leite (lactose, gordura, proteína e sólidos totais (ST)) e efetuada a contagem de células somáticas (CCS) no leite, respectivamente. Os sólidos não gordurosos (SNG) foram calculados pela diferença entre os (ST) e a gordura ( $\mathrm{SNG}=\mathrm{ST}-$ gordura). Uma amostra do leite sem conservante foi coletada para determinação de uréia no leite (NUL), refrigerada e precipitada com ácido tricloroacético ao $10 \%$, centrifugada a 3000rpm por 15 minutos e no sobrenadante se determinou a uréia por método enzimático.
A análise estatística incluiu análise da variância para comparar os períodos, correlação de Pearson entre os componentes do leite, a CCS e os parâmetros metabólicos e ruminais, e regressão linear entre $\mathrm{pH}$ ruminal e da urina para predizer o $\mathrm{pH}$ ruminal através do pH urinário. As análises foram realizadas no pacote computacional SAS (2001).

\section{RESULTADOS E DISCUSSÃO}

Durante a lactação, ocorrem mudanças nos componentes do leite (BACHMAN, 1992). Entretanto, em vacas de alta produção é possível que este fato não aconteça ou que as variações não sejam facilmente determinadas (KENNELLY et al., 2000). Isto foi observado no presente trabalho. Possivelmente pela relativa similaridade genética dos animais, o controle do manejo alimentar e a fase da lactação. A análise de variância (Andeva) não mostrou efeito do período sobre os componentes do leite (Tabela 1).

Os valores apresentados para os componentes do leite estão em acordo com os valores descritos para a raça Holandesa e animais de alta produção (KENNELLY et al., 2000). Como esperado, os valores de gordura exibem a maior variação entre os períodos. Os valores médios de proteína nas semanas 5 e 8 ficaram abaixo dos níveis mínimos aceitos na Instrução Normativa 51 para o leite de conjunto (MAPA, 2002). FREDEEN (1996) apresenta, como possível causa de baixos teores de proteína, o baixo consumo de matéria seca e o desequilíbrio na ingestão de proteína bruta na dieta. No presente experimento, esta situação pode estar mais relacionada à redução do consumo de matéria seca que acontece no pósparto do que os níveis de proteína na ração. Em nenhum dos rebanhos, as amostras individuais estudadas atingiram o mínimo de 8,4\% de SNG exigido pela norma para o leite de conjunto. A queda foi maior na semana 5 , quando o valor esteve 0,61 abaixo do mínimo. Ao comparar os valores de sólidos totais com os descritos para a raça, é possível encontrar que os baixos valores de lactose são os responsáveis pela queda nos SNG. Na mesma área geográfica de estudo, NORO (2004) encontrou similar comportamento dos SNG num estudo feito com mais de 350.000 dados individuais. Se considerar que o leite de conjunto (IN-51) representa a soma do leite individual das vacas em lactação à situação poderia apresentar uma grande perda econômica. De uma parte, não se estaria alcançando o teor de SNG adotado pela norma; de outra parte, os laticínios não irão implementar um sistema de pagamento por qualidade, como se espera seja estabelecido no Brasil, para um produto abaixo dos padrões mínimos exigidos (SANTOS, 2005). 
Tabela 1 - Média, erro padrão e valor de P para a análise de variância entre períodos da composição do leite e os principais indicadores de qualidade do leite em diferentes períodos da primeira fase da lactação em vacas de alta produção.

\begin{tabular}{|c|c|c|c|c|c|}
\hline \multirow{2}{*}{ Componente } & \multicolumn{4}{|c|}{ Semana de lactação } & \multirow{2}{*}{ Andeva $\mathrm{P}>\mathrm{F}$} \\
\hline & 2 & 5 & 8 & 11 & \\
\hline Gordura (\%) & $3,62 \pm 0,10$ & $3,77 \pm 0,12$ & $3,59 \pm 0,09$ & $3,55 \pm 0,09$ & 0,4445 \\
\hline Proteína (\%) & $2,95 \pm 0,04$ & $2,84 \pm 0,04$ & $2,86 \pm 0,05$ & $2,91 \pm 0,04$ & 0,2892 \\
\hline Lactose (\%) & $4,56 \pm 0,03$ & $4,56 \pm 0,04$ & $4,58 \pm 0,05$ & $4,65 \pm 0,03$ & 0,2745 \\
\hline STOTAL $^{1}(\%)$ & $11,66 \pm 0,13$ & $11,57 \pm 0,14$ & $11,47 \pm 0,12$ & $11,58 \pm 0,12$ & 0,8049 \\
\hline $\mathrm{SNG}^{2}(\%)$ & $8,03 \pm 0,10$ & $7,79 \pm 0,11$ & $7,88 \pm 0,10$ & $8,03 \pm 0,11$ & 0,2940 \\
\hline $\mathrm{IPG}^{3}$ & $0,84 \pm 0,02$ & $0,78 \pm 0,03$ & $0,82 \pm 0,03$ & $0,80 \pm 0,02$ & 0,3492 \\
\hline $\left.\mathrm{NUL}^{4} \mathrm{mmol} / \mathrm{L}\right)$ & $3,49 \pm 0,28$ & $3,74 \pm 0,30$ & $3,26 \pm 0,34$ & $3,42 \pm 0,39$ & 0,7923 \\
\hline Produção ${ }^{5}$ & $32,6 \pm 1,3$ & $34,8 \pm 2,11$ & $34,13 \pm 1,65$ & $29,85 \pm 1,58$ & 0,1808 \\
\hline $\mathrm{CCS}^{6}$ & $296 \pm 70,18$ & $521 \pm 139,7$ & $271 \pm 90,34$ & $411 \pm 114,0$ & 0,3223 \\
\hline
\end{tabular}

${ }^{1} \mathrm{STOTAL}=$ Sólidos totais, ${ }^{2} \mathrm{SNG}=$ Sólidos não gordurosos, ${ }^{3} \mathrm{IPG}=$ Índice proteína Gordura, ${ }^{4} \mathrm{NUL}=$ Nitrogênio uréico no leite, ${ }^{5}$ Produção= Média invididual diária em (L). ${ }^{6} \mathrm{CCS}=$ Contagem de células somáticas em (10 ${ }^{3}$ células $\left./ \mathrm{mL}\right)$, Andeva= Análise de variância.

Os baixos valores de lactose não têm explicação desde a ótica do manejo nutricional, toda vez que o cálculo da ração foi efetuado considerando a energia líquida de lactação (EL). Uma hipótese poderia ser que esteja acontecendo degradação da lactose no tempo percorrido entre o amostragem e a análise laboratorial. Isto é pouco provável, já que as amostras foram analisadas antes do tempo máximo recomendado (SARLE, 2000), além de que todas as amostras foram coletadas com conservante. O índice proteína gordura do leite (IPG) relativamente baixo reflete os períodos críticos de baixos teores de proteína, assim como níveis de gordura no limite mínimo aceito. Os valores de uréia no leite (NUL), estiveram abaixo de valores críticos que pudessem indicar desequilíbrios na relação energia:proteína (HERDT, 2000). A contagem média de células somáticas esteve abaixo dos limites máximos considerados pela IN-51 (MAPA, 2002) e, em alguns casos, inferior aos padrões internacionais (250mil células $\mathrm{mL}^{-1}$ ) para períodos similares da lactação (SANTOS, 2005).

Na tabela 2, são apresentados os valores médios dos parâmetros ruminais e metabólitos avaliados no período pós-parto. Não houve diferença significativa entre os períodos e todos os indicadores encontramse dentro dos valores de referência. Os valores de TRAM esperados sob condições ruminais normais devem estar perto dos três minutos (SORIANO et al., 2000). Os resultados indicam uma excelente dinâmica na microbiota ruminal já que o tempo médio foi inferior a dois minutos. Uma microbiota ruminal ativa e um $\mathrm{pH}$ perto da neutralidade garantem um processo digestivo dinâmico e uma geração de ácidos graxos e síntese de proteína microbiana adequada (VAN SOEST, 1994). No presente trabalho, o $\mathrm{pH}$ esteve em acordo com os valores fisiológicos para dietas com alto conteúdo de fibra, entre 6,4-7,0. Quando a dieta é mais rica em concentrados, espera-se um $\mathrm{pH}$ na faixa de 6,0 a 6,6.

Tabela 2 - Médias ajustadas e erro padrão e valor de P para a análise de variância entre períodos para os indicadores do ambiente ruminal e valores séricos de metabólitos associados com a fisiologia do rúmen, em diferentes períodos da primeira fase da lactação em vacas leiteiras de alta produção.

\begin{tabular}{lcccc}
\hline & & \multicolumn{2}{c}{ Semanas de lactação } & Andeva \\
\cline { 2 - 5 } Indicador & 2 & 5 & 8 & 11 \\
& $2,28 \pm 0,19$ & $1,99 \pm 0,21$ & $1,96 \pm 0,22$ & $1,63 \pm 0,13$ \\
TRAM* rúmen & $6,71 \pm 0,05$ & $6,76 \pm 0,07$ & $6,81 \pm 0,06$ & $6,80 \pm 0,05$ \\
pH rúmen & $0,58 \pm 0,04$ & $0,74 \pm 0,07$ & $0,78 \pm 0,06$ & $0,69 \pm 0,06$ \\
BHB** sérico mmol/L & $3,84 \pm 0,26$ & $3,96 \pm 0,28$ & $3,92 \pm 0,31$ & $4,36 \pm 0,29$ \\
Uréia sérica mmol/L & & & 0,4712 \\
\hline
\end{tabular}

*TRAM= Tempo de redução de azul de metileno em (min), **BHB = $\beta$-hidroxibutirato

Ciência Rural, v.36, n.2, mar-abr, 2006. 
No presente estudo, o valor médio do $\mathrm{pH}$ ruminal alcançou um valor de 6,77. Atualmente considera-se importante garantir a estabilidade do $\mathrm{pH}$ ruminal não só pelo fato da prevenção da acidose ruminal, mas também por seu efeito sobre a biohidrogenação da qual se derivam os níveis de CLA (ácido linoléico conjugado) de grande valor econômico pelas suas propriedades biomédicas (BAUMGARD et al., 2002).

Devido ao fato de as maiores variações na composição do leite serem originadas no manejo alimentar e que este manejo, por sua vez, está estreitamente relacionado com o balanço nutricional, a determinação de indicadores bioquímicos que permitam relacionar estes com a fermentação ruminal constitui uma opção para captar informação sobre balanço na formulação da dieta (FREEDEN, 1996). Na procura de metabólitos que pudessem ser associados com o ambiente ruminal e o equilíbrio da ração, foram analisadas BHB e NUS. Os valores encontrados (Tabela 2) estão em acordo com os valores de referência (OETZEL, 2001; KIDA, 2003). Não foram observados valores elevados de BHB que pudessem indicar desequilíbrios energéticos. Por outro lado, os valores de uréia, permitem deduzir que o ambiente ruminal não teve elevados teores de proteína degradável ou de fontes de nitrogênio não protéico em excesso. Os metabólitos BHB e NUS foram também relacionados com os principais componentes do leite e com os indicadores do rúmen. Os resultados apresentam valores considerados como "normais", portanto, poder-se-ia concluir que os indicadores dos processos digestivos no rúmen não explicam de forma adequada os baixos teores dos componentes do leite no estudo. Como esperado, foi encontrada uma alta correlação entre o NUS e o NUL ( $r=0,755 ; \mathrm{P}<0,001)$. Este achado é útil para considerar o uso de NUL na determinação dos níveis de uréia no sangue, concordando com outros autores (HERDT, 2000; KIDA, 2003).
Na tabela 3, são apresentados os valores do teste de correlação de Pearson entre os componentes do leite e os parâmetros metabólicos e ruminais. A NUS se apresenta como um indicador importante nos estudos sobre a composição do leite. Foram achadas correlações moderadas e significativas entre NUS e SNG ( $\mathrm{r}=0,38399, \mathrm{P}<0,001)$, NUS e ST $(\mathrm{r}=0$,20683, $\mathrm{P}<0,0236)$, e entre NUS e proteína no leite $(r=-0,21413, P<0,0268)$. Não foi observada correlação significativa entre outros indicadores e os componentes do leite, indicando que tanto a glândula mamária, como o rúmen e o sangue, ainda que estejam metabolicamente inter-relacionados, possuem dinâmicas fisiológicas individuais (KIDA, 2003).

Levando em conta as dificuldades associadas com a determinação do $\mathrm{pH}$ do rúmen, e com base em estudos sobre a possibilidade de avaliação indireta do $\mathrm{pH}$ do sangue a partir do $\mathrm{pH}$ da urina (ORTOLANI, 2002) foi determinado no presente trabalho o $\mathrm{pH}$ da urina, na tentativa de avaliar o $\mathrm{pH}$ ruminal a partir desse valor na urina. Estudos recentes avaliam o uso da determinação do pH da urina no manejo de diferentes situações originadas no ambiente ruminal, tais como acidose ruminal e intoxicação por amônia decorrente do excesso de administração de uréia na dieta (HERDT, 2000; ORTOLANI, 2002). Os valores de $\mathrm{pH}$ urinário encontrados foram 8,35 $\pm 0,3 ; 8,20 \pm 0,24$; $8,26 \pm 0,12$ e 8,23 $\pm 0,23$ para as semanas 2, 5 , 8 e 11, respectivamente. Este valor corresponde ao esperado para bovinos com dieta de alto conteúdo de fibra (ORTOLANI, 2002). Foi estabelecida uma equação de regressão para avaliar o $\mathrm{pH}$ do rúmen a partir do $\mathrm{pH}$ da urina: $\mathrm{pH}$ rúmen $=6,914-0,01952 \times \mathrm{pH}$ urina. Não houve significância estatística nesta regressão $(\mathrm{P}=0,87)$ o qual junto ao baixo coeficiente determinação $\left(\mathrm{R}^{2}=0,026\right)$ não permite o uso confiável da equação. É possível que maior número de dados e a determinação

Tabela 3 - Coeficiente de correlação de Pearson entre as variáveis metabólicas e os indicadores ruminais e metabólicos com os componentes do leite e a contagem de células somáticas (CCS).

\begin{tabular}{|c|c|c|c|c|}
\hline \multirow{2}{*}{ Componente do leite } & \multicolumn{4}{|c|}{ Parâmetros metabólicos e ruminais } \\
\hline & TRAM $^{1}$ & $\mathrm{pH}$ & $\mathrm{NUS}^{2}$ & $\mathrm{BHB}^{3}$ \\
\hline Gordura & $-0,12654^{\mathrm{ns}}$ & $0,09165^{\mathrm{ns}}$ & $-0,13323^{\text {ns }}$ & $-0,05347^{\text {ns }}$ \\
\hline Proteína & $-0,18811^{\mathrm{ns}}$ & $0,04478^{\text {ns }}$ & $-0,21413^{*}$ & $-0,15381^{\text {ns }}$ \\
\hline Lactose & $0,04042^{\mathrm{ns}}$ & $0,06372^{\mathrm{ns}}$ & $0,00467^{\mathrm{ns}}$ & $-0,07177^{\mathrm{ns}}$ \\
\hline Sólidos totais & $-0,02936^{\mathrm{ns}}$ & $0,03951^{\mathrm{ns}}$ & $0,20683 *$ & $-0,01972^{\text {ns }}$ \\
\hline Sólidos não-gordurosos & $0,08437^{\mathrm{ns}}$ & $-0,03847^{\mathrm{ns}}$ & $0,38399 * *$ & $0,0657^{\mathrm{ns}}$ \\
\hline CCS & $-0,03249^{\mathrm{ns}}$ & $-0,13082^{\text {ns }}$ & $0,05318^{\mathrm{ns}}$ & $-0,09962^{\mathrm{ns}}$ \\
\hline
\end{tabular}

${ }^{\mathrm{ns}}=$ não significativo $(\mathrm{P}>0,05) ; *$ = significativo a $5 \%(\mathrm{P} \leq 0,05) ; * *=$ significativo a $1 \%(\mathrm{P} \leq 0,01)$.

${ }^{1}$ TRAM= Tempo de redução de azul de metileno em (min), ${ }^{2}$ NUL= Nitrogênio uréico no Sangue, ${ }^{3}$ BHB = $\beta$-hidroxibutirato

Ciência Rural, v.36, n.2, mar-abr, 2006. 
de horas fixas de coleta com relação às refeições possam melhorar o coeficiente e significância do modelo.

\section{CONCLUSÃO}

Não se podem relacionar indicadores de ambiente ruminal e metabólico com os componentes químicos do leite, nem com a CCS de vacas de alta produção da raça Holandesa na primeira fase da lactação.

\section{AGRADECIMENTOS}

Ao Conselho Nacional de Desenvolvimento Científico e Tecnológico (CNPq), pelo financiamento do presente projeto através do contrato 470897-2003.

\section{REFERÊNCIAS}

BACHMAN, K.C. Managing milk composition. In: VAN HORN, H.H.; WILCOX, C.J. Large dairy herd management. Champaign: American Dairy Science Association, 1992. Cap.35, p.336-346.

BAUMGARD, L.H. et al. Effects of conjugated linoleic acids (CLA) on tissue response to homeostatic signals and plasma variables associated with lipid metabolism in lactating dairy cows. Journal of Animal Science, v.80, p.1285-1293, 2002.

FREDEEN, A.H. Considerations in the nutritional modification of milk composition. Animal Feed Science and Technology, v.59, p.185-197, 1996.

HERDT, T.H. Variability characteristics and test selection in herd level nutritional and metabolic profile testing. Veterinary Clinics of North America: Food Animal Practice, v.16, n.2, p.387-403, 2000.

IBARRA, A.A. Sistema de pagamento do leite por qualidade, visão global. In: CONGRESSO BRASILEIRO DE QUALIDADE DO LEITE, 2004, Passo Fundo, RS. Anais... Passo Fundo, 2004. p.72-87.

KENNELLY, J.J. et al. Milk composition in the cow. Edmonton, Alberta: Faculty of Extension, University of Alberta, 2000. 20p.

KIDA, K. Relationships of metabolic profiles to milk production and feeding in dairy cows. Journal Veterinary Medicine Science, v.65, n.6, p.671-677, 2003.
KLEEN, J.L. et al. Subacute ruminal acidosis (SARA): a review. Journal Veterinary Medicine, Series A, v.50, p.406-414, 2003.

MAPA. Governo Federal Brasil. Instrução Normativa 51. Brasília, 2002. 45p.

MARTIN, S.A. Manipulation of ruminal fermentation with organic acids: a review. Journal of Animal Science, v.76, p.3123-3132, 1998.

NORO. G. Fatores ambientais que afetam a produção e a qualidade do leite em rebanhos ligados a cooperativas gaúchas. 2004. 92f. Dissertação (Mestrado Ciências Veterinárias) - Programa de Pós-graduação em Ciências Veterinárias, UFRGS, Porto Alegre.

OETZEL, G.R. Herd-based biological testing for metabolic disorders. In: ANNUAL CONFERENCE AMERICAN ASSOCIATION OF BOVINE PRACTITIONERS, 34., 2001, Vancouver, BC. Proceedings... Nancouver: AABP, 2001. p.1-12.

ORTOLANI, E. Diagnóstico de doenças nutricionais e metabólicas por meio de exame de urina em ruminantes. In: GONZÁLEZ, F.D. (Ed). AVALIAÇÃO METABÓLICONUTRICIONAL DE VACAS LEITERIAS POR MEIO DE FLUÍDOS CORPORAIS, 2002, Gramado, RS. Anais... Gramado, RS.: UFRGS, 2002. p.18-26.

SANTOS, M.V. Utilizando a CCS e a CBT como ferramenta em tempos de pagamento por qualidade do leite. Parte 1. Capturado em 22 ags. 2005. Online. Disponível na Internet: http://www.milkpoint.com.br/mn/radarestecnicos/

SARLE. Serviço de análises de rebanhos leiteiros. Guia e recomendações para a coleta, manejo e envio de amostras do leite. Passo Fundo, RS: UPF, 2000. 25p.

SAS Institute SAS ${ }^{\oplus}$ User's Guide: Statistics. Cary, NC, 2001. 285p.

SORIANO F.D. et al. Milk production and composition, rumen fermentation parameters, and grazing behavior of dairy cows supplemented with different forms and amounts of corn grain. Journal of Dairy Science, v.83, p.1520-1529, 2000.

VAN SOEST P.J. Nutritional ecology of the ruminant. Salem, OR: O \& B Books, 1994. 485p. 